\title{
Белоус Н.Н. \\ Анализ функциональных зависимостей физических величин как элемент метапредметного подхода в обучении
}

Брянский государственный университет

(Россия, Брянск)

doi 10.18411/spc-04-03-2018-02

idsp 000001:spc-04-03-2018-02

Формы и методы преподавания физики во многом зависят от уровня математической подготовки учащихся. Разрабатывая календарно-тематическое планирование, необходимо учитывать знания учащихся и по математике. Проиллюстрируем реализацию межпредметных связей физики и математики на примере использования понятий «функция», «график функции», «графический метод решения».

Зная виды пропорциональности, соотношения между математическими величинами можно проводить соответствующие преобразования и с физическими величинами, не анализируя их природу, а используя пропорциональные зависимости (в основном прямую и обратную). Что особенно актуально при работе в классах не физико-математического профиля.

Обеспечение использования на уроках физики и математики общего "математического языка" во многом решает задачу формирования межпредметных знаний, четкости и осознанности при усвоении понятий, процессов, явлений и их описания.

Физические закономерности, изучаемых процессов, обычно записываются в школе аналитически, с помощью формул или таблично, далеко не всегда учителя видят необходимость в рассмотрении графической интерпретации процесса. Это приводит к тому, что учащиеся воспринимают функциональную зависимость формально. Использование графического способа дополняет аналитический, возможностью иллюстрации на графике хода физической закономерности, что наглядно раскрывает динамику процесса.

Так, например, для абсолютного большинства учащихся не представляет сложностей математический материал, касающийся свойств линейной функции, ее графика: общий случай: $\mathrm{y}=\mathrm{kx}+\mathrm{b}(\mathrm{k}, \mathrm{b} \neq 0)$, частные случаи:

1) $\quad$ Если $\mathrm{k}=0$, то графиком функции будет прямая $\mathrm{y}=\mathrm{b}$ параллельная оси $\mathrm{OX}$ и проходящая через точку $(0 ; \mathrm{b})$;

2) Если $\mathrm{b}=0$, то график функции - прямая $\mathrm{y}=\mathrm{kx}$, проходящая через точки $\mathrm{c}$ координатами $(0 ; 0)$ и $(\mathrm{x} ; \mathrm{kx})$;

3) $\quad$ Если $\mathrm{k}, \mathrm{b}=0$, то график функции - прямая $\mathrm{y}=0$, совпадающая с осью OX.

Соответственно, включение этого материала в урок на этапе актуализации знаний или при постановке проблемы создаст условия для ситуации успеха для большинства учащихся, а не только тех, кто в состоянии самостоятельно осваивать учебный материал.

Примерами подобных заданий могут быть:

по математике: Построить графики следующих функций a )y= $-2 \mathrm{x}+2 ; \mathrm{b}) \mathrm{y}=(1 / 4)$ $\mathrm{x}-1$; c) $\mathrm{y}=6 \mathrm{x} ; \mathrm{d}) \mathrm{y}=4$;

по физике: Тема «Теплообмен». Количество теплоты, выделяющееся при сгорании топлива, рассчитывают по формуле $\mathrm{Q}=\mathrm{qm}$. Постройте графики зависимости $\mathrm{Q}(\mathrm{m})$ для следующих видов топлива: a) каменного угля (q=2,7·107Дж/кг); b) нефти $(\mathrm{q}=4,4 \cdot 106 Д ж / к г)$. Данного вида подход удобно использовать при изучении процессов нагревания и охлаждения, измерений агрегатных состояний вещества и др. 
Тема «Равноускоренное движение». Зависимость координаты х равномерно движущегося тела от времени $\mathrm{t}$ имеет вид: $\mathrm{x}=\mathrm{x} 0+\mathrm{vt}$. Постройте график этой зависимости для случаев: а) $\mathrm{v}=3 \mathrm{~m} / \mathrm{c}, \mathrm{x} 0=4 \mathrm{~m}$; b) х0 $=0, \mathrm{v}=8 \mathrm{~m} / \mathrm{c}$.

Не меньший интерес представляет работа, связанная с анализом графиков зависимостей физических величин.

Используя математические знания учащихся о нахождении координаты у точки на графике по известной координате $\mathrm{x}$, о составлении уравнения с числовыми коэффициентами по графику линейной функции, о нахождении коэффициента $\mathrm{k}$, в общем случае $\mathrm{k}=\frac{\mathrm{y}_{2}-\mathrm{y}_{1}}{\mathrm{x}_{2}-\mathrm{x}_{1}}$, и в частном $\mathrm{k}=\mathrm{y} / \mathrm{x}$, можно оптимизировать решения физических задач, приводя математические аналогии.

Рассмотрим примеры заданий

По математике: 1) Дан график линейной функции рис. 1.

Найти: а) у, если х $=4$, б) х, если $у=4$.

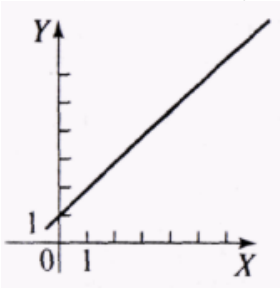

(puc.1)

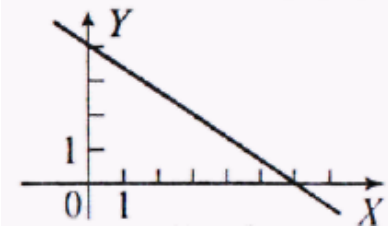

(puc.2)

2) Дан график линейной функции рис.2.

Найти коэффициенты $\mathrm{k}, \mathrm{b}$ для функции вида $\mathrm{y}=\mathrm{kx}+\mathrm{b}$.

По физике:

1. По графику (рис. 3), выражающему зависимость силы тока в проводнике от напряжения на его концах, определить напряжение U на концах проводника при силе тока в нем $1=3 \mathrm{~A}$.

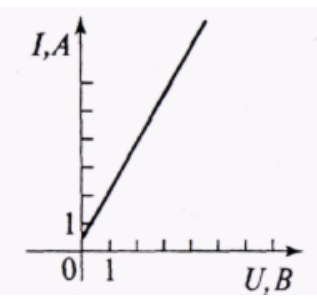

(рис.3)

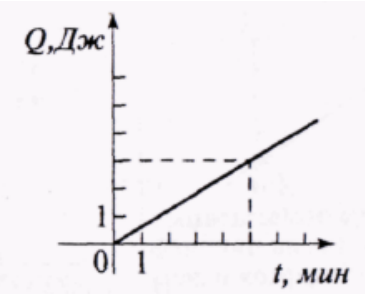

(рис.4)

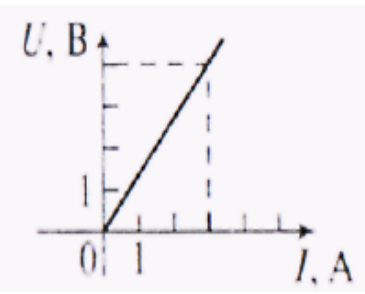

(рис.5)

2. По графику зависимости количества теплоты Q. выделившегося в проводнике c током, от времени прохождения тока $t$ (рис. 4) определить, какое количество теплоты $\mathrm{Q}$ выделилось за время $\mathrm{t}=5$ мин.

3. Дано: график (рис.5) зависимости напряжения на концах проводника U от силы тока в нем I.Найти: Коэффициенты b и k для математического выражения, соответствующего этому графику. Сопротивление R по графику.

В этом случае $\mathrm{R}(\mathrm{U} / \mathrm{I})$ равно $\mathrm{k}$.

Опыт работы показал, что общий подход к анализу графиков физических функциональных зависимостей создает благоприятные условия для формирования общих умений в работе с графиками функций на уроках физики и математики.

Исследования специалистов показывают перспективность решения графических задач путем более полной реализации межпредметных связей, способствующих систематизации знаний учащихся, выработке у них умений и навыков обобщенного, надпредметного характера. Однако, эпизодическое использование знаний одного предмета при изучении другого не способно выработать обобщенные знания и умения. 
Особая роль в решении этого вопроса принадлежит формированию общих понятий на межпредметной основе.

Приведем еще пример, понятие производной может быть использовано не только при обобщенном введении понятий скорость и ускорение, но и при анализе понятий заряд - ток, ЭДС электромагнитной индукции - поток вектора напряженности, а так же и к уравнениям описывающим: механические колебания, процессы в колебательном контуре и цепи переменного тока и т.д.

Таким образом, от вопроса межпредметных связей мы переходим к вопросу о применении концепции развития универсальных учебных действий в системе общего образования.

Под универсальными учебными действиями (УУд) подразумевают способность обучаемого к саморазвитию и самосовершенствованию путем сознательного и активного присвоения нового социального опыта; совокупность действий учащегося, обеспечивающих его культурную идентичность, социальную компетентность, способность к самостоятельному усвоению новых знаний и умений, включая организацию этого процесса.

Система формирования универсальных учебных действий существенно расширяет традиционное содержание, обеспечивает преемственность образовательного процесса и является основой для формирования метапредметных подходов в образовании.

$$
* * *
$$

1. Белоус Н.Н., Кучин С.М. Графический метод как способ реализации межпредметных связей физики и математики.// Актуальные проблемы гуманитарных и естественных наук. - Москва, 2010. - No7. c. $259-262$

2. Овчарова Д. Я. Интеграция физики с предметами школьного курса в рамках внедрения ФГОС [Электронный ресурс] / Д. Я. Овчарова // Педагогическое мастерство. - 2015. - URL: https://www.pedm.ru/categories/10/articles

3. Яворук О.А. Теоретико-методические основы построения интегративных курсов в школьном естественнонаучном образовании / О. А. Яворук. - Челябинск, 2000. - с. 332

\section{Бирюкова Н.С., Куликова А.О. \\ Воспитательный процесс в любительском театральном коллективе}

Сургутский государственный университет (Россия, Сургут)

doi 10.18411/spc-04-03-2018-03

idsp 000001:spc-04-03-2018-03

Любительские творческие объединения дают возможность для слаженного максимально целостного постижения мира, приобщения к ценностям культуры и искусства. В разновидностях досуговой художественной деятельности, максимально комплексным видом творчества является театр. Процесс воспитания средствами театрального искусства -целенаправленный процесс, направленный на воспитание нравственных, моральных, патриотических, духовных и пр. качеств личности, взглядов и убеждений, жизненных ценностей, правил и манеры поведения, а также навыков и привычек. Воспитание - это формирование личности с помощью создания специальных педагогических условий, методов и средств [2].

Воспитательный процесс- это процесс взаимодействия, в котором в соответствии с целями и задачами самой личности и общества совершается организованное воспитательное влияние и взаимодействие, имеющее своей целью формирование личности, организацию и стимулирование активной деятельности воспитуемых по овладению ими социальным и духовным опытом, ценностями и отношениями [6].Специфика воспитательного процесса заключается в своеобразии 